Case Report

\title{
Mediastinal Ectopic Pancreas with Abundant Endocrine Cells Coexisting with Mediastinal Cyst and Thymic Hyperplasia
}

\author{
Yosinta Snak (D), ${ }^{1}$ Ery Kus Dwianingsih, ${ }^{1}$ Auliya Suluk Brilliant Sumpono, ${ }^{1}$ Rovi Panji, ${ }^{1}$ \\ Afif Rahman, ${ }^{2}$ Ahmad Ghozali $\left(\mathbb{1},{ }^{1}\right.$ and Samir S. Amr $\mathbb{D}^{3}$ \\ ${ }^{1}$ Department of Anatomical Pathology, Faculty of Medicine, Universitas Gadjah Mada, Yogyakarta, Indonesia \\ ${ }^{2}$ Department of Radiology, Faculty of Medicine, Universitas Gadjah Mada, Yogyakarta, Indonesia \\ ${ }^{3}$ Department of Pathology and Laboratory Medicine, King Fahad Specialist Hospital, Dammam, Saudi Arabia
}

Correspondence should be addressed to Samir S. Amr; samir.amr48@gmail.com

Received 8 January 2018; Accepted 19 February 2018; Published 27 May 2018

Academic Editor: Fang Fan

Copyright (C) 2018 Yosinta Snak et al. This is an open access article distributed under the Creative Commons Attribution License, which permits unrestricted use, distribution, and reproduction in any medium, provided the original work is properly cited.

\begin{abstract}
Mediastinal ectopic pancreas is a rare condition with only 28 cases reported in the literature. Here we report a 21-year-old female patient who presented with dyspnea and intermittent severe chest pain of 7 years' duration. Computerized tomography scan (CT-scan) of the chest revealed a mediastinal cyst. The cyst was resected and it demonstrated on histopathological examination the presence of pancreatic tissue with increased number of islets of Langerhans, coexistent with mediastinal cyst and thymic hyperplasia. We made a review of all previously reported cases of this entity.
\end{abstract}

\section{Introduction}

Ectopic pancreas is defined as pancreatic tissue which grows outside its normal location and without vascular or other anatomical connections to the pancreas. It had been also named in the literature as heterotopic, accessory, or aberrant pancreas [1]. It is a congenital anomaly found in approximately $2 \%$ of autopsies, and most (70-90\%) are located within the gastrointestinal tract $[2,3]$. Development of pancreas within the mediastinum is quite rare. To our knowledge, 28 cases have been reported in the literature, showing variable clinical, radiographic, and histopathological characteristic. Thymic hyperplasia is defined as an enlarged thymus composed of normal thymic lobules with preserved corticomedullary differentiation [2]. It may coexist with a mediastinal cyst [3]. Here we report a patient who presented with mediastinal ectopic pancreas with hyperplasia of islets of Langerhans and coexisted with mediastinal cyst and thymic hyperplasia.

\section{Case Report}

A 21-year-old female patient was admitted with chronic dyspnea and intermittent severe chest pain of 7 years' duration.
Chest X-ray showed a mediastinal mass. Thoracic CT-scan revealed a cystic lesion, $6.7 \times 7.5 \mathrm{~cm}$ located in inferior part of the anterior mediastinum (Figure 1). Laboratory workup including hematological, biochemical, and hormone profiles was all within normal limits. Surgical resection of this cystic mass was performed.

Gross pathological examination of the mass showed 2 fragments of opened soft cystic tissue, $6 \times 5 \mathrm{~cm}$ and $4 \times 3 \mathrm{~cm}$ in size. A thickened white to brown area within the wall of the cyst was noted. Histopathological examination revealed hyperplastic thymic tissue arranged into lobules, separated by fibrous tissue septa. The corticomedullary differentiation of thymus was well preserved, and Hassall's corpuscles were readily identified. Some empty and eosinophilic fluid filled spaces lined with cuboidal to columnar cells were identified. In the thickened area, pancreatic tissue, with both exocrine and endocrine elements, was identified. It consisted of acinar exocrine cells with interlobular ducts and abundant endocrine cells (Islets of Langerhans) (Figure 2). No features of fat necrosis were seen, and no cystic formations within the pancreatic tissue were noted. There were no teratomatous elements such as skin, neural tissue, bone, cartilage, and endodermal components. No malignancy was 


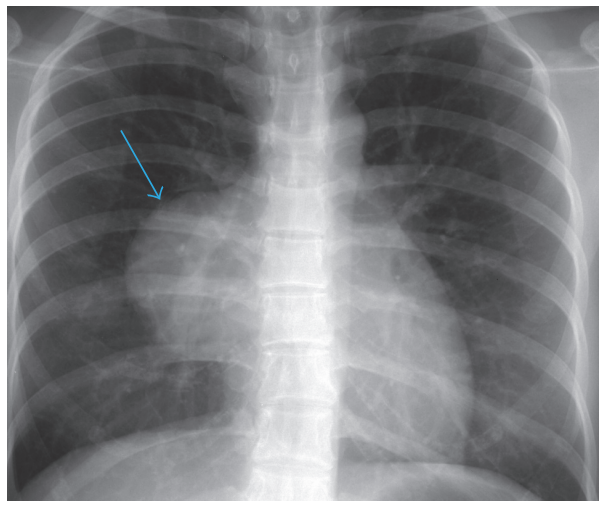

(a)

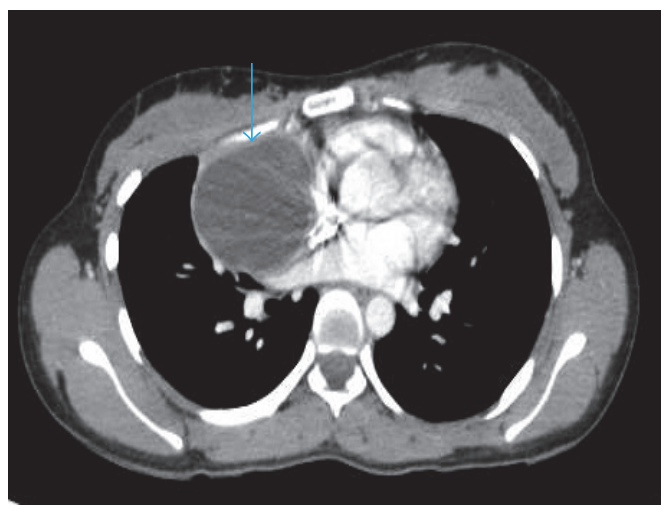

(b)

Figure 1: (a) Chest X-ray showed $6 \times 4.5 \mathrm{~cm}$ white opaque lesion in mediastinal area (blue arrow) and (b) CT-scan revealed hypodense mass $6.7 \times 7.5 \mathrm{~cm}$, suggesting inferoanterior mediastinal cyst (blue arrow). Encapsulated cystic lesion compressed adjacent aorta and pericardium.

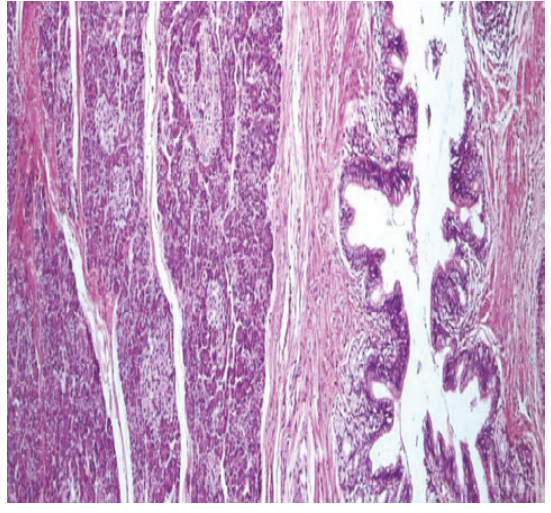

(a)

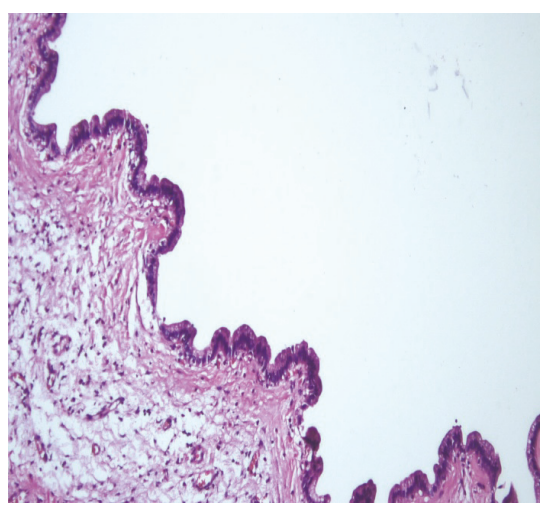

(d)

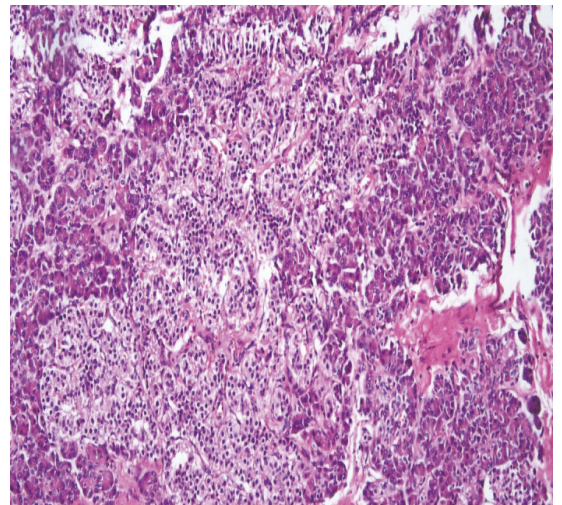

(b)

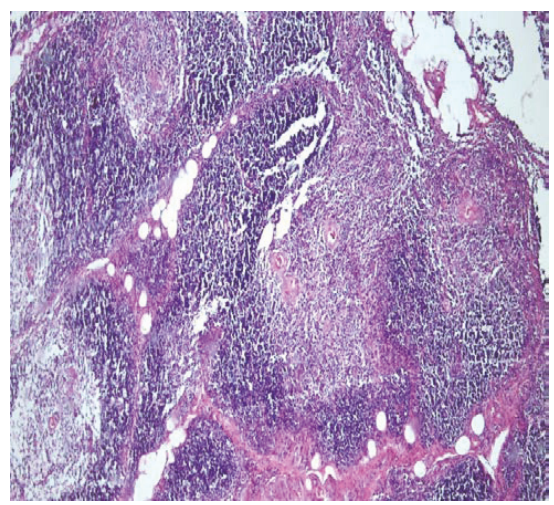

(e)

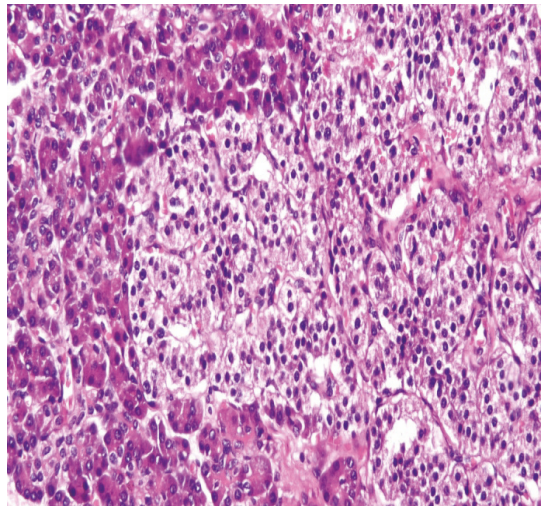

(c)

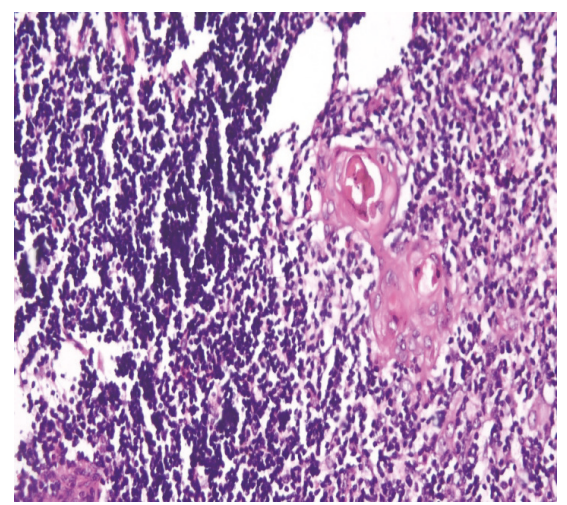

(f)

Figure 2: (a) An Island of pancreas tissue bordered by thick fibrous tissue with pancreatic interlobular duct around it (H\&E-4x). (b) Pancreas tissue consists of exocrine gland with eosinophilic granular cytoplasm and endocrine cells (Islets of Langerhans) (H\&E-10x). (c) Increase in the endocrine portion (Islets of Langerhans) of pancreatic tissue (H\&E-40x). (d) Mediastinal cyst lined by simple cuboid and columnar epithelium (H\&E-10x). (e) Hyperplasia of thymic gland was observed (HE-4x). (f) Normal appearance of lymphocytes and Hassall's corpuscles (H\&E-10x).

observed. Immunohistochemical staining for insulin showed strongly positive Beta cells of the islets of Langerhans within the ectopic pancreatic tissue (Figure 3). The patient had an uneventful postoperative course. Her last follow-up visit at six months showed normal chest CT- scan and no evidence of recurrence of the mass. 


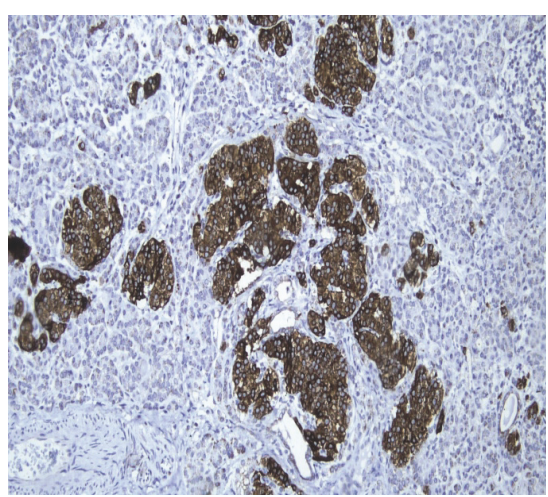

(a)

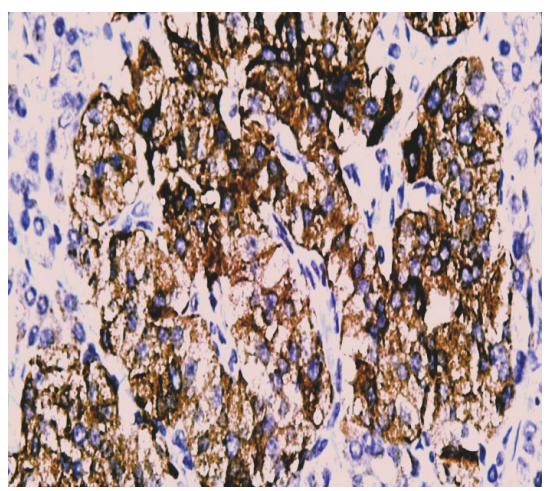

(d)

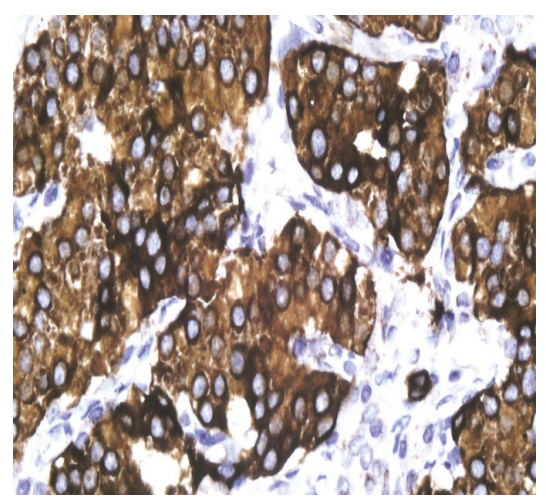

(b)

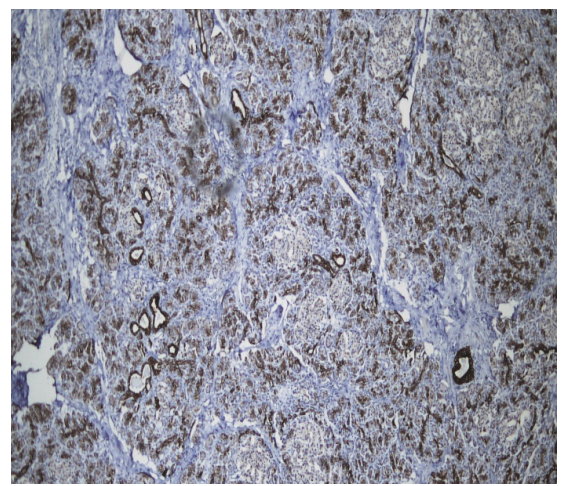

(e)

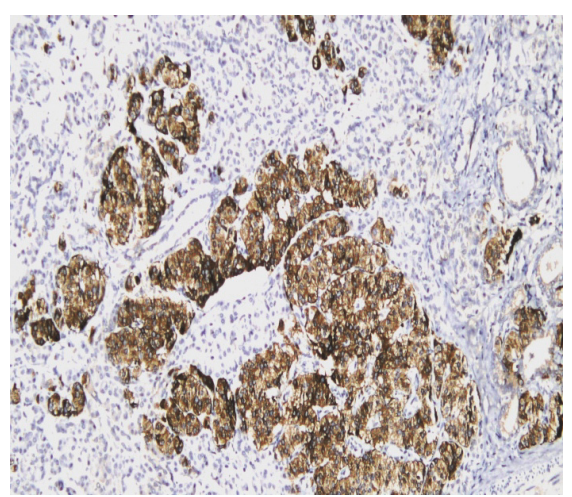

(c)

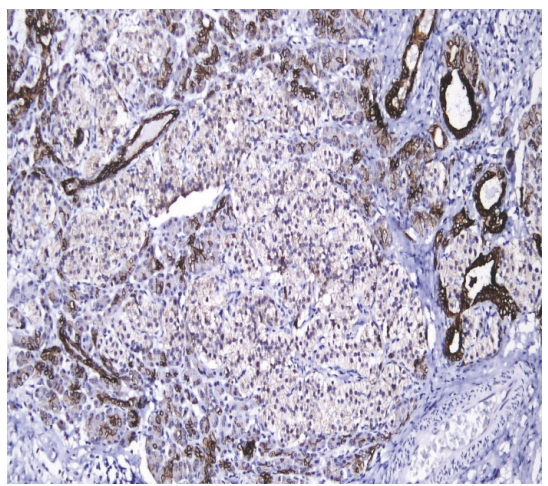

(f)

FIGURE 3: Immunohistochemical staining. (a and b) High expression of insulin in pancreatic beta cells of islets of Langerhans (10x-40x). (c and d) Strong positivity of chromogranin in islets of Langerhans (10x-40x). (e and f) Cytokeratin showed strong positivity in acinic cells and pancreatic duct; meanwhile endocrine cells showed very weak expression $(4 \mathrm{x}-10 \mathrm{x})$.

\section{Discussion}

Most cases of ectopic pancreas are located in the gastrointestinal tract, such as the stomach, duodenum, jejunum, and ileum [2]. However, it can be located in other sites, such as the gallbladder, esophagus, common bile duct, spleen, mesentery, and the mediastinum. The histogenesis of a mediastinal ectopic pancreas is currently unknown [4]. However, there are two main theories regarding the embryogenesis of this abnormal development. The first theory is the pluripotent epithelial cells of the ventral primary foregut that undergo anomalous differentiation, called heteroplasia, and this may lead to the formation of ectopic pancreatic tissue in the mediastinum. The second theory is that some cells from the pancreatic bud may migrate and locate at a different site [2].

There had been 28 cases of mediastinal ectopic pancreas reported in the world literature, demonstrating variable clinical, radiographic, and histopathological characteristic [2-25]. These cases are summarized in Table 1. It usually occurs in young adult, as in the current patient, with average age of 30 years, ranging from 5 to 66 years. There is slight female preponderance $(58.6 \%)$ over males $(41.4 \%)$, with a male to female ratio of $1: 1.4$. Clinical manifestations include chest pain, reported in 15 patients $(51.7 \%)$, dyspnea in 8 patients (27.6\%), and cough in 6 patients $(20.7 \%)$. Other symptoms include pneumonia, hemoptysis, fever, throat discomfort, night sweat, shoulder pain, and neck swelling [5, 18, 23, 25]. Asymptomatic cases were also identified in 4 cases $(13.4 \%)$ $[3,6,13,20]$.

Almost all patients with mediastinal ectopic pancreas showed unremarkable laboratory and physical examination. One case reported to have high blood pressure, fever, and leukocytosis [11]. Our patient showed common symptoms such as chest pain and dyspnea, but interestingly, she had these symptoms for the last 7 years. To our knowledge, this is the longest duration of the symptoms of this condition. Some patients had an opposite scenario with the disease manifesting itself for a short period of time of 2-4 weeks prior to the diagnosis $[24,25]$.

All reported cases of mediastinal ectopic pancreas were located in the anterior mediastinum. The size of the mass varied from $2 \times 3 \times 4 \mathrm{~cm}$ to $20 \times 15 \mathrm{~cm} \mathrm{[7,25].} \mathrm{More} \mathrm{than}$ $75 \%$ of the lesions were cystic, including 6 cases $(27 \%)$ that had a solid component, as in this case. There were four cases that were solid without cystic changes. One case out of these four was reported to develop adenocarcinoma arising from the ectopic pancreatic tissues [18, 23, 24]. All benign cases were fully recovered after the operation and no recurrence was reported even years after surgery $[20,24]$. The patient who developed adenocarcinoma died 15 months after surgery [16]. 


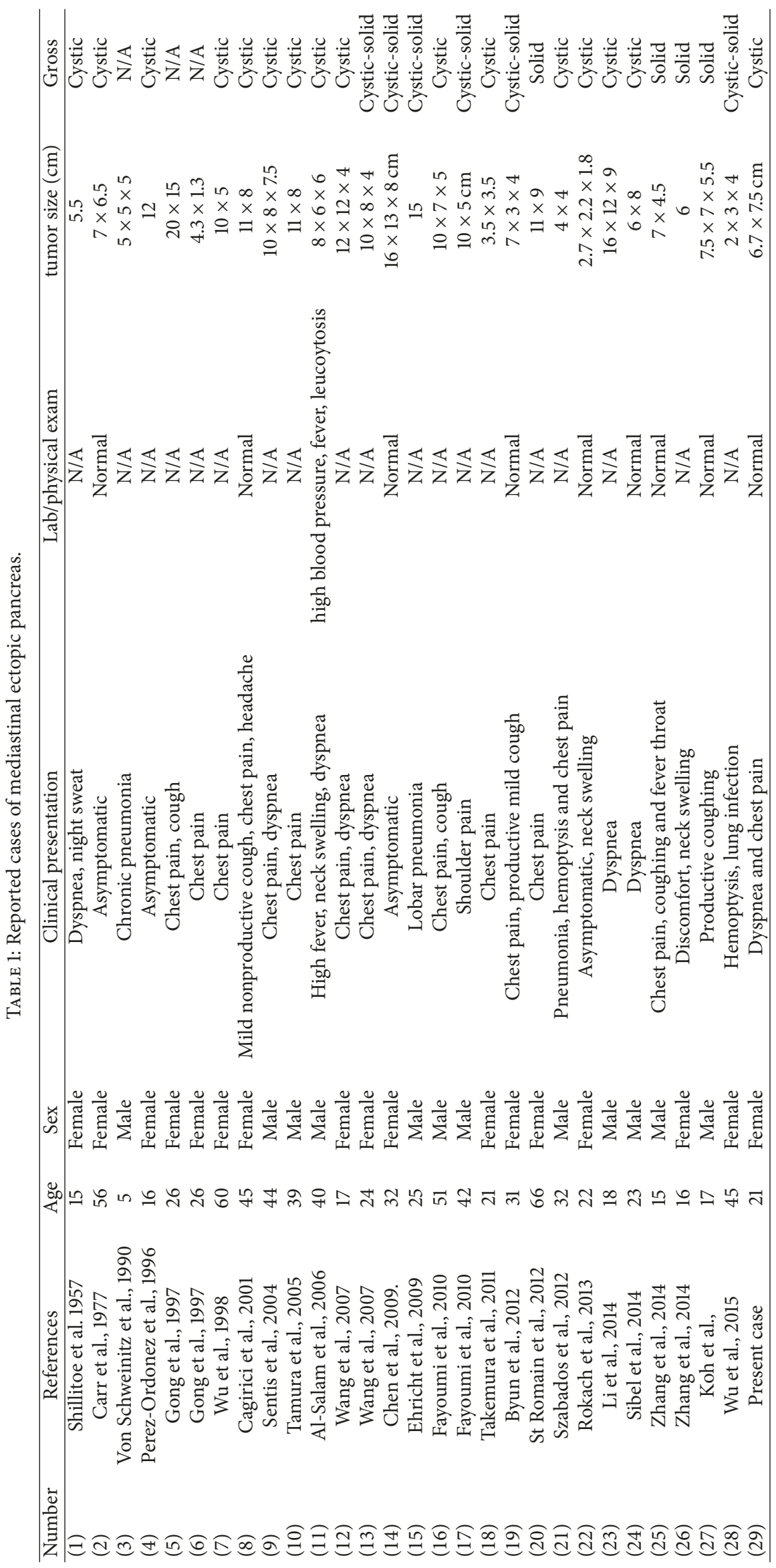


Radiologically, the cystic area and the solid portion of the lesions generally showed mild to moderate enhancement with contrast material. Cystic lesions in mediastinum may be clinically diagnosed as mediastinal abscess, benign teratomatous cyst, and true mediastinal cyst. Due to its common cystic nature, mediastinal ectopic pancreas currently can be suggested as one of the items in the differential diagnosis of mediastinal cystic lesions. Regarding the solid mediastinal ectopic pancreas, CT-scan cannot distinguish it from other solid masses such as thymoma, lymphoma, or malignant teratoma. In all these conditions, the diagnosis can be established only after surgery and histopathological examination [20].

Mediastinal cystic teratoma should be considered in the histological differential diagnosis of this lesion. Teratomas in general can contain pancreatic tissue in addition to other ectodermal, endodermal, and mesodermal elements. In one study of 469 teratomas from various sites, 17 cases contained pancreatic tissue, the majority of which (11 cases) were located in the anterior mediastinum [26]. Single case reports mediastinal teratomas with either increased exocrine pancreatic activity [27] or associated with aberrant islet differentiation or nesidioblastosis [28].

Our case has common cystic lesion as other mediastinal ectopic pancreas cases. Interestingly, the ectopic pancreatic tissue has a abundant component in its endocrine cells of the islets of Langerhans. These cells stained positively for insulin by immunohistochemical staining. The patient did not have a low glucose level and did not suffer from hypoglycemia. The adjacent thymus showed hyperplasia with well-preserved corticomedullary structures. This coexistence of thymic hyperplasia and ectopic pancreatic tissue had not been reported previously. We assume that, due to long and chronic course of the disease of 7 years, the thymus was induced to hyperplastic and reactive changes.

\section{Conclusion}

Mediastinal ectopic pancreas is extremely rare entity. Up to now, 28 cases have been reported, mostly occurring in young adults, and females are more prone to have the anomaly. Frequent clinical manifestation is chest pain and dyspnea. Benign cystic lesions are the most common feature of this entity. Mediastinal ectopic pancreas with increase in endocrine cells that coexisted with mediastinal cyst and thymic hyperplasia has never been reported previously.

\section{Conflicts of Interest}

The authors declare that there are no conflicts of interest regarding the publication of this paper.

\section{References}

[1] Y. J. Kim, W. S. Kim, J.-E. Cheon et al., "Unusual thymic hyperplasia mimicking lipomatous tumor in an eight-year-old boy with concomitant pericardial lipomatosis and right facial hemihypertrophy," Korean Journal of Radiology, vol. 12, no. 3, pp. 376-381, 2011.
[2] D. von Schweinitz, C. Wittekind, and J. Freihorst, "Mediastinal sequestration with ectopic pancreatic tissue," Surgery in infancy and childhood, vol. 45, no. 4, pp. 249-250, 1990.

[3] B. Perez-Ordonez, D. E. Wesson, C. R. Smith, and S. L. Asa, "A pancreatic cyst of the anterior mediastinum," Modern Pathology, vol. 9, no. 3, pp. 210-214, 1996.

[4] U. Cagirici, M. Ozbaran, A. Veral, and H. Posacioglu, "Ectopic mediastinal pancreas," European Journal of Cardio-Thoracic Surgery, vol. 19, no. 4, pp. 514-515, 2001.

[5] Shillitoe A. J. and J. E. Wilson, "Enterogenous cyst of thorax with pancreatic tissue as a constituent," Journal of Thoracic Surgery, vol. 34, no. 6, pp. 810-814, 1957.

[6] M. J. T. Carr, A. K. Deiraniya, and P. A. Judd, "Mediastinal cyst containing mural pancreatic tissue," Thorax, vol. 32, no. 4, pp. 512-516, 1977.

[7] N. Gong, "Ectopic pancreas in within thorax: two case reports," Chin J Thorac Cardiovasc Surg, p. 308, 1997.

[8] J. Wu and Y. Chen, "Ectopic pancreas in anterior mediastinal with pseudocyst: one case report," Chinese Journal of Clinical Thoracic and Cardiovascular Surgery, vol. 14, p. 214, 1998.

[9] M. Iglesias Sentís, J. Belda Sanchís, J. Gimferrer Garolera, M. Catalán Biel, M. Rubio Garay, and J. Ramírez Ruiz, "Mediastinal Enteric Cyst: Unusual Clinical Presentation and Histopathology," Arch Bronconeumol, vol. 40, pp. 185-187, 2004.

[10] Y. Tamura, M. Takahama, K. Kushibe, and S. Taniguchi, "Ectopic pancreas in the anterior mediastinum," The Japanese Journal of Thoracic and Cardiovascular Surgery, vol. 53, no. 9, pp. 498-501, 2005.

[11] S. Al-Salam and M. Al Ashari, "Ectopic pancreatic tissue in the anterior mediastinum [2]," Virchows Archiv, vol. 448, no. 5, pp. 661-663, 2006.

[12] W. Wang, K. Li, W. Qin, H. Sun, and C. Zhao, "Ectopic pancreas in mediastinum: Report of 2 cases and review of the literature," Journal of Thoracic Imaging, vol. 22, no. 3, pp. 256-258, 2007.

[13] Z.-H. Chen, R.-S. Yu, F. Dong, and X.-J. Wang, "CT findings of an ectopic pancreas in the anterior mediastinum," Korean Journal of Radiology, vol. 10, no. 5, pp. 527-530, 2009.

[14] A. Ehricht, F. Pützschler, K. Weißmann, and M. Klenske, "Ectopic pancreatic tissue within a mediastinal cyst - A rare clinical manifestation," Zentralblatt fur Chirurgie - Zeitschrift fur Allgemeine, Viszeral- und Gefasschirurgie, vol. 134, no. 2, pp. 178-181, 2009.

[15] S. Fayoumi, L. Al-Husseini, R. Jalil, and S. Abbasi, "Ectopic pancreatic tissue in the thoracic cavity: Report of two cases," The Annals of Thoracic Surgery, vol. 90, no. 2, pp. e25-e27, 2010.

[16] M. Takemura, K. Yoshida, and K. Morimura, "Thoracoscopic resection of thoracic esophageal duplication cyst containing ectopic pancreatic tissue in adult," Journal of Cardiothoracic Surgery, vol. 6, no. 1, article no. 118, 2011.

[17] C. S. Byun, I. K. Park, H. Kim, and W. Yu, "Ectopic pancreas with hemorrhagic cystic change in the anterior mediastinum," The Korean Journal of Thoracic and Cardiovascular Surgery, vol. 45, no. 2, pp. 131-133, 2012.

[18] P. St. Romain, G. Muehlebach, I. Damjanov, and F. Fan, "Adenocarcinoma arising in an ectopic mediastinal pancreas," Annals of Diagnostic Pathology, vol. 16, no. 6, pp. 494-497, 2012.

[19] S. Szabados, L. Lénárd, T. Tornóczky, E. Várady, and Z. Verzár, "Ectopic pancreas tissue appearing in a mediastinal cyst," Journal of Cardiothoracic Surgery, vol. 7, no. 1, article no. 22, 2012. 
[20] A. Rokach, G. Izbicki, M. Deeb et al., "Ectopic pancreatic pseudocyst and cyst presenting as a cervical and mediastinal mass - case report and review of the literature," Diagnostic Pathology, vol. 8, no. 1, article no. 176, 2013.

[21] W. W. Li, W. J. van Boven, R. R. Jurhill, P. I. Bonta, J. T. Annema, and B. A. de Mol, "Ectopic pancreas in a giant mediastinal cyst," The Clinical Respiratory Journal, vol. 10, no. 1, pp. 125-128, 2016.

[22] S. Arslan, E. Arslan, M. Şanli, K. Bakir, and L. Elbeyli, "Ectopic mediastinal pancreas," Turkish Journal of Thoracic and Cardiovascular Surgery, vol. 22, no. 1, pp. 192-195, 2014.

[23] L. Zhang, L.-Q. Peng, J.-Q. Yu et al., "Ectopic pancreas in the anterior mediastinum: A report of two cases and review of the literature," Oncology Letters, vol. 7, no. 4, pp. 1053-1056, 2014.

[24] H. M. Koh, J. W. Chang, S. Y. Jeong et al., "Ectopic Pancreas Presenting as a Solid Mediastinal Mass," International Journal of Surgical Pathology, vol. 23, no. 7, pp. 585-588, 2015.

[25] L. Wu, L. Lin, L. Jiang, and G. Jiang, "Ectopic Pancreas in Mediastinum Presenting as Hemoptysis," The Annals of Thoracic Surgery, vol. 100, no. 6, p. 2368, 2015.

[26] K. Suda, K. Mizuguchi, A. Hebisawa, T. Wakabayashi, and S. Saito, "Pancreatic tissue in teratoma," Archives of Pathology \& Laboratory Medicine, vol. 108, no. 10, pp. 835-837, 1984.

[27] F. Stella and F. Davoli, "Giant mediastinal mature teratoma with increased exocrine pancreatic activity presenting in a young woman: A case report," Journal of Medical Case Reports, vol. 5, article no. 238, 2011.

[28] T. Agrawal, A. J. Blau, W. J. Chwals, and A. S. Tischler, "A Unique Case of Mediastinal Teratoma with Mature Pancreatic Tissue, Nesidioblastosis, and Aberrant Islet Differentiation: a Case Report and Literature Review," Endocrine Pathology, 2015. 


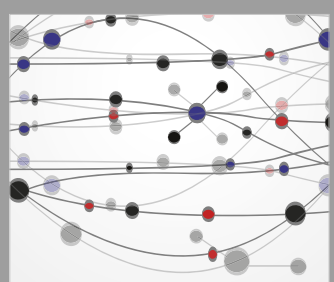

The Scientific World Journal
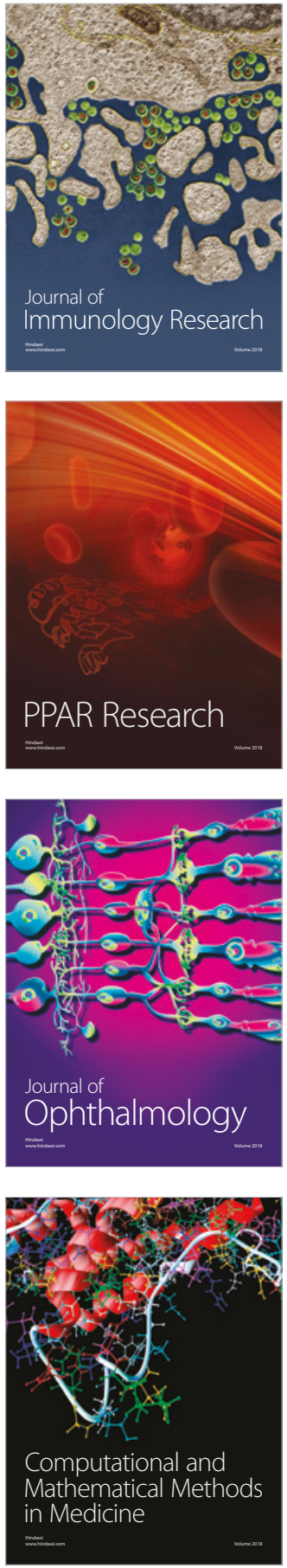

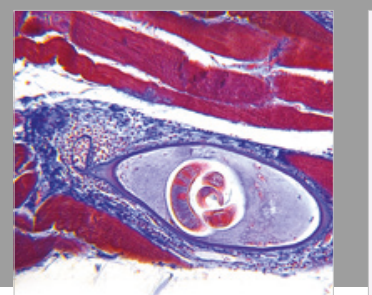

Gastroenterology Research and Practice

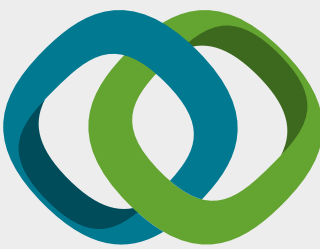

\section{Hindawi}

Submit your manuscripts at

www.hindawi.com
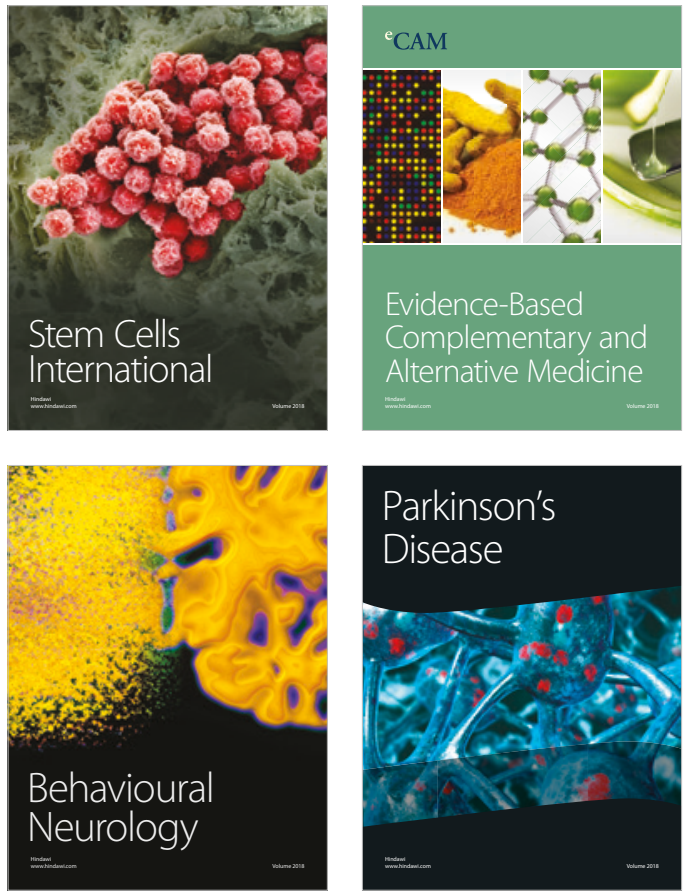

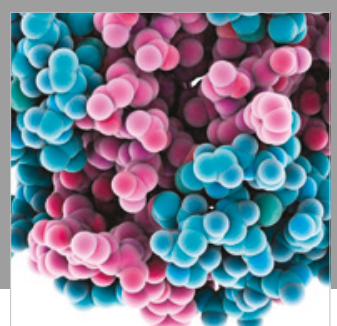

ournal of

Diabetes Research

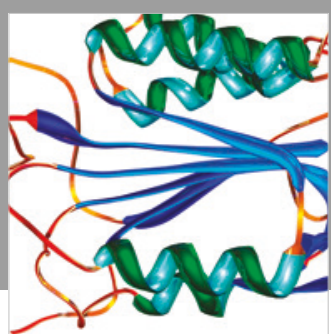

Disease Markers
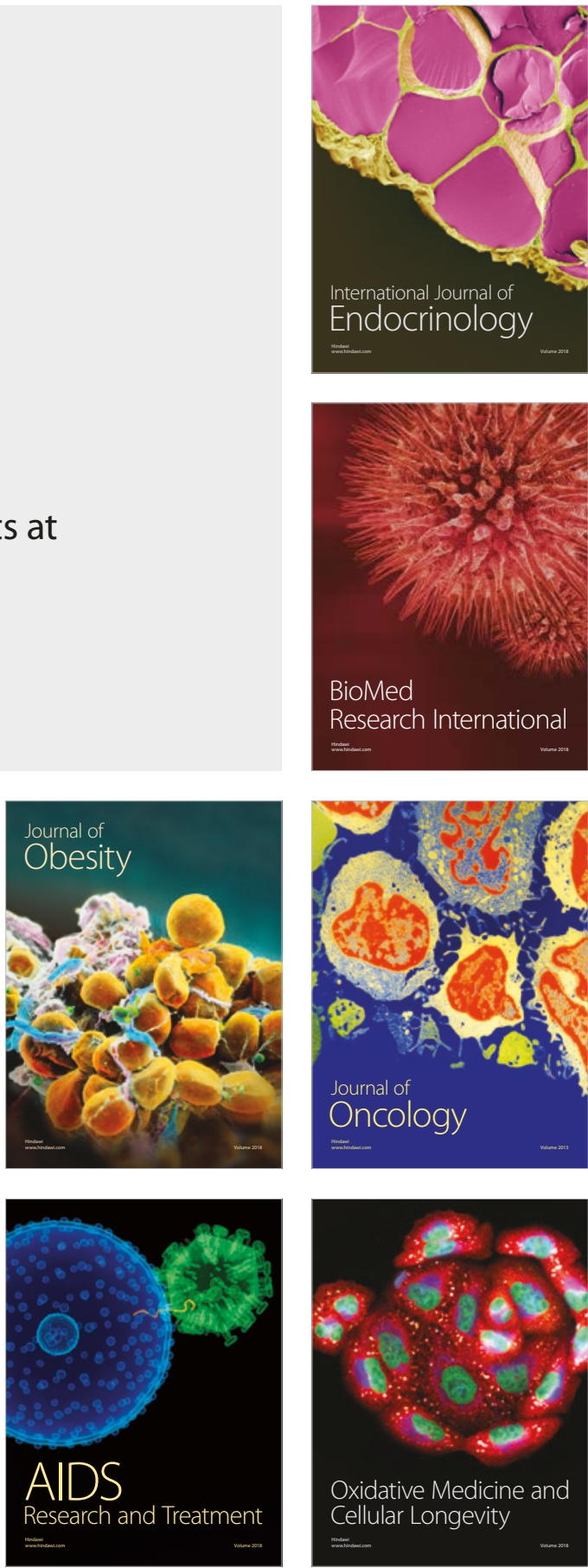